\title{
PENERAPAN GROUNDED RESEARCH PADA PENDATAAN PASIEN DI SASANA TRESNA WERDHA RIA PEMBANGUNAN
}

\author{
Septina Wulandari ${ }^{1}$, Maria Cleopatra ${ }^{2}$, Diyan Parwatiningtyas ${ }^{3}$ \\ Program Studi Teknik Informatika, Fakultas Teknik dan Ilmu Komputer, \\ Universitas Indraprasta PGRI \\ Jalan Raya Tengah No 80, Kelurahan Gedong, Pasar Rebo, Jakarta Timur \\ septiw1998@gmail.com¹, mariacleopatra1313@gmail.com², diane.tyas@gmail.com³
}

\begin{abstract}
Abstrak
Perkembangan teknologi merupakan sebuah perkembangannya yang berjalan dengan cepat setiap waktunya, manusia sebagai pencipta dan pengguna teknologi tersebut tidak dapat menolak laju arus perkembangan teknologi untuk digunakan dalam kehidupan sehari-hari. Pada kajian ini, merupakan latar belakang bagaimana pentingnya pendataan pada panti werdha perlu diperhatikan pada sistem yang terdapat pada sasana tresna werdha ria pembangunan di cibubur belum terkomputerisasi dengan baik. Metode penelitian yang digunakan adalah metode grounded (grounded research) untuk melakukan penelitian yang bersifat kualitatif. Hasil dari penelitian ini adalah sistem informasi yang dapat membantu sasana tresna werdha ria pembangunan untuk menghasilkan data pendaftaran pasien, mengelola data pribadi pasien, rekam medis pasien, data-data staf yang bekerja dan administrasi pembayaran pasien secara cepat, efektif serta efesien. Hal tersebut dapat memudahkan dalam penyampaian laporan untuk diserahkan kepada kepala sasana tresna werdha ria pembangunan.
\end{abstract}

Kata Kunci: Sistem Informasi, Data, Pendataan, Pasien, Panti Werdha, Java

\begin{abstract}
Technological development is a development that runs rapidly every time, humans as creators and users of these technologies cannot resist the flow of technological developments for use in everyday life. In this study, it is the background of how the importance of data collection at nursing homes needs to be considered in the system contained in Sasana Tresna Werdha Ria pembangunan in Cibubur that has not been computerized properly. The research method used is the grounded method (grounded research) to conduct qualitative research. The result of this study is an information system that can assist the development of the Sasana Tresna Werdha Ria Pembangunan Hospital to produce patient registration data, manage patient personal data, patient medical records, work staff data and patient payment administration quickly, effectively and efficiently. This can facilitate the submission of reports to be submitted to the head of the Sasana Tresna Werdha Ria Pembangunan
\end{abstract}

Keywords: information Systems, Data collection, Data, Patients, Nursing Homes, Java

\section{PENDAHULUAN}

Pemanfaatan teknologi di segala bidang sudah dikembangkan dengan sedemikian rupa yang bertujuan untuk membantu kinerja manusia supaya lebih cepat dibanding menggunakan cara yang bersifat tradisional. Dalam penelitian (Fadil \& Ruhiat, 2018) Penerapan Teknologi Informasi sudah masuk ke berbagai bidang dan mulai dirasakan manfaatnya. Peranan sistem informasi sangat berperan penting dalam membantu kinerja dalam pemrosesan data yang cepat dan dapat disajikan dalam sebuah laporan yang berguna bagi sebuah organisasi, perusahaan, lembaga swadaya atau yayasan yang didirikan untuk tujuan sosial seperti panti werdha. Dalam pemrosesan pengolahan data alat yang sangat berperan untuk mengolah data ialah komputer, agar data yang diolah dapat dilakukan dengan efektif dan efesien dalam menyimpan dan memberikan informasi secara akurat, tepat, dan cepat yang sangat berguna bagi yayasan sosial. Semakin banyak data yang masuk banyak juga data yang harus diolah. Menurut Dengan menggunakan komputer diharapkan data yang disajikan yaitu berupa informasi akan lebih akurat dan jelas. Kebutuhan akan komunikasi dan informasi sekarang ini dalam sebuah panti mutlak diperlukan. Semakin menuntut untuk adanya 
suatu sistem yang cepat, mudah, murah, efektif dan efisien. Khususnya dalam konteks ini adalah hadirnya media komunikasi dan informasi yang dihadirkan didunia yayasan panti. Dengan hadirnya perancangan sistem serta mengikuti perkembangan teknologi dimana akan dikembangkan pada Sasana Tresna Werdha RIA Pembangunan di cibubur berbasis Java sehingga memudahkan staf dalam pengolahan data pasien serta dapat melakukan pengarsipan data secara efektif dan efesien. Adapun sarana yang dimaksud adalah suatu perancangan yang digunakan untuk pendaftaran pasien baru pada Sasana Tresna Werdha RIA Pembangunan. Saat ini sistem yang berjalan pada penerimaan pasien belum terkomputerisasi dan masih menggunakan berkas dalam menggunakan media kertas pendaftaran pasien baru. Hal tersebut dinilai kurang efektif mengingat perkembangan teknologi sekarang ini sudah berkembang secara pesat. Dengan menggunakan sistem yang terkomputerisasi sangat memudahkan dalam proses pendaftaran pasien serta dalam penyimpanan data penting pasien seperti rekam medis pasien fungsi rekam medis menurut (Andi Suprianto, 2018) Rekam medis digunakan sebagai acuan pasien, terutama pada saat pasien berobat selanjutya.. bahkan saat ini tidak sedikit bahkan segala sesuatunya sudah terkomputerisasi sangat bermanfaat bagi pihak yayasan dan memudahkan para staf Sasana Tresna Werdha RIA Pembangunan. Dengan hadirnya perancangan sistem pada Sasana Tresna Werdha RIA Pembangunan perlu ditetapkan suatu teknik dalam mengelolah informasi data yang ada agar menjadi suatu hal yang bermanfaat untuk membantu pengelolaan data dalam memberikan informasi kepada setiap bagian staf serta ketua panti werdha.

\section{PENELITIAN RELEVAN}

Penelitian oleh (Supriyanto \& Matsea, 2018). Rancang Bangun Aplikasi Pendaftaran Pasien Online Dan Pemeriksaan Dokter Di Klinik Pengobatan Berbasis Web. Bertujuan untuk memudahkan pasien dalam mendaftarkan dirinya atau anggota keluarganya tanpa harus pasien mengantri dan menunggu lama. Memudahkan pegawai klinik dalam melayani pendaftaran pasien. Meningkatkan efisiensi waktu dalam hal pelayanan terhadap pasien.

Penelitian oleh (Anastasia \& Syarifrudin, 2018). Perancangan Database Relasional Data Lansia Pant. Penelitian ini untuk memudahkan dalam pengelolaan data penghuni, data iuran, data mutasi penghuni, data penyumbang, data sumbangan, dan data pegawai, serta meminimalisasikan resiko kerusakan data dan kehilangan data, dan memudahkan proses pengaksesan data dengan mudah dan cepat.

Penelitian relevan ini menjadi acun penting supaya mengenal tentang apa yang akan diteliti dan penelitian terdahulu ini sangat bermanfaat, yang membedakan penelitian ini dengan penelitian relevan adalah sistem yang dibuat lebih baik dalam penerapannya dan penggunaan lebih mudah dengan tampilan layar yang memudahkan pengguna.

\section{METODE PENELITIAN}

Penelitian menurut (Dari, 2015) dengan memahami bagaimana pengguna melakukan pekerjaannya dari awal hingga (bagaimana mulai melakukan hingga mengakhiri aktivitas, data, informasi dan laporan yang dibutuhkan dan dihasilkannya) dan membuat laporan hasil analisis. Dalam metode penelitian ini berfungsi sebagai pengembangan sistem informasi. Metode yang digunakan menggunakan grounded (grounded research) dan metode survey.

\section{Metode Kepustakaan}

Dalam metode kepustakaan pengumpulan data dan informasi, kutipan-kutipan dari berbagai sumber buku, jurnal, peraturan perundang-undangan, serta dari hasil laporan dan skripsi. Merupakan bahan yang berkaitan dengan penelitian ini, kutipan-kutipan tersebut digunakan sebagai referensi yang bersifat relevan dan membangun untuk menganalisa dan mengobservasi penelitian yang sedang dilakukan.

\section{Survei}

Survei yang dilakukan dalam penelitian dengan mengunjungi langsung lokasi penelitian yang berlokasi di Cibubur. 


\section{Wawancara}

Wawancara dilakukan di Sasana Tresna Werdha RIA Pembangunan yang terletak di daerah Cibubur dengan di dampingi oleh ibu Dwi Astuti sebagai penanggung jawab pembimbing penelitian sekaligus wakil kepala Sasana Tresna Werdha RIA Pembangunan. Wawancara yang dilakukan secara langsung pengenai pendataan pasien akan dikaji secara menyeluruh berdasarkan kebutuhan dalam penelitian. Sehingga menghasilkan penelitian yang efektif dan relevan.

\section{HASIL DAN PEMBAHASAN}

Melalui hasil penelitian peneliti dapat mengusulkan aturan bisnis sesuai dengan ketentuan Sasana Tresna Werdha RIA Pembangunan yang sebelumnya belum terkomputerisasi menjadi terkemputerisasi dengan baik. Dengan begitu mengenai aturan bisnis yang baru dapat memudahkan kinerja staf yang bertugas dalam penginputan data dan pencarian data secara efektif dan optimal.

Auran bisnis sistem yang diusulkan:

1. Sub kelompok jabatan fungsional tata usaha menginput data calonpasien mengenai informasi untuk melakukan pendaftaran pasien pada Sasana Tresna Werdha RIA Pembangunan dan calonpasien melakukan pembayaran pendaftaran sesuai tarif kamar yang diplih oleh calon pasien.

2. Setelah calon pasien melakukan pembayaran pendaftaran calon pasien sudah resmi menjadi pasien Sasana Tresna Werdha RIA Pembangunan dan akan menerima bukti pembayaran pendaftaran yang akan diserahkan oleh Sub kelompok jabatan fungsional administrasi.

3. Sub kelompok jabatan fungsional tata usaha menginput data diri pasien agar disimpan dalam database data pasien sebagai arsip data pasien.

4. Sub kelompok jabatan fungsional tata usaha menginput rekam medis pasien agar disimpan kedalam database rekam medis pasien sebagai arsip data pasien.

5. Sub kelompok jabatan fungsional administrasi bertugas menerima pembayaran yang dilakukan pasien, pembayaran yang dilakukan dapat berupa biaya tinggal selama perperiode di Sasana Tresna RIA Werdha Pembangunan yang diserahkan pada setiap pasien dan dapat berupa laporan administrasi pembayaran yang digunakan sebagai laporan diserahkan kepada Kepala pimpinan Sasana Tresna Werdha RIA Pembangunan.

6. Untuk pendataan staf yang mendaftar dan telah di terima data staf akan di input dan disimpan kedalam database untuk menghasilkan laporan data staf yang akan diserahkan kepada kepala pimpinan Sasana Tresna Werdha RIA Pembangunan.

Perancangan basis data adalah proses untuk menentukan isi dan pengaturan data yang dibutuhkan untuk mendukung berbagai rancangan sistem (Syarifudin, 2018).

Rancangan sistem yang diusulkan:

Diagram aliran data yang disingkat DAD (data flow diagram yang disingkat DFD) adalah sebuah alat perancangan yang menggunakan simbol- simbol untuk menjelaskan sebuah proses (Ladjamudin, 2013). 


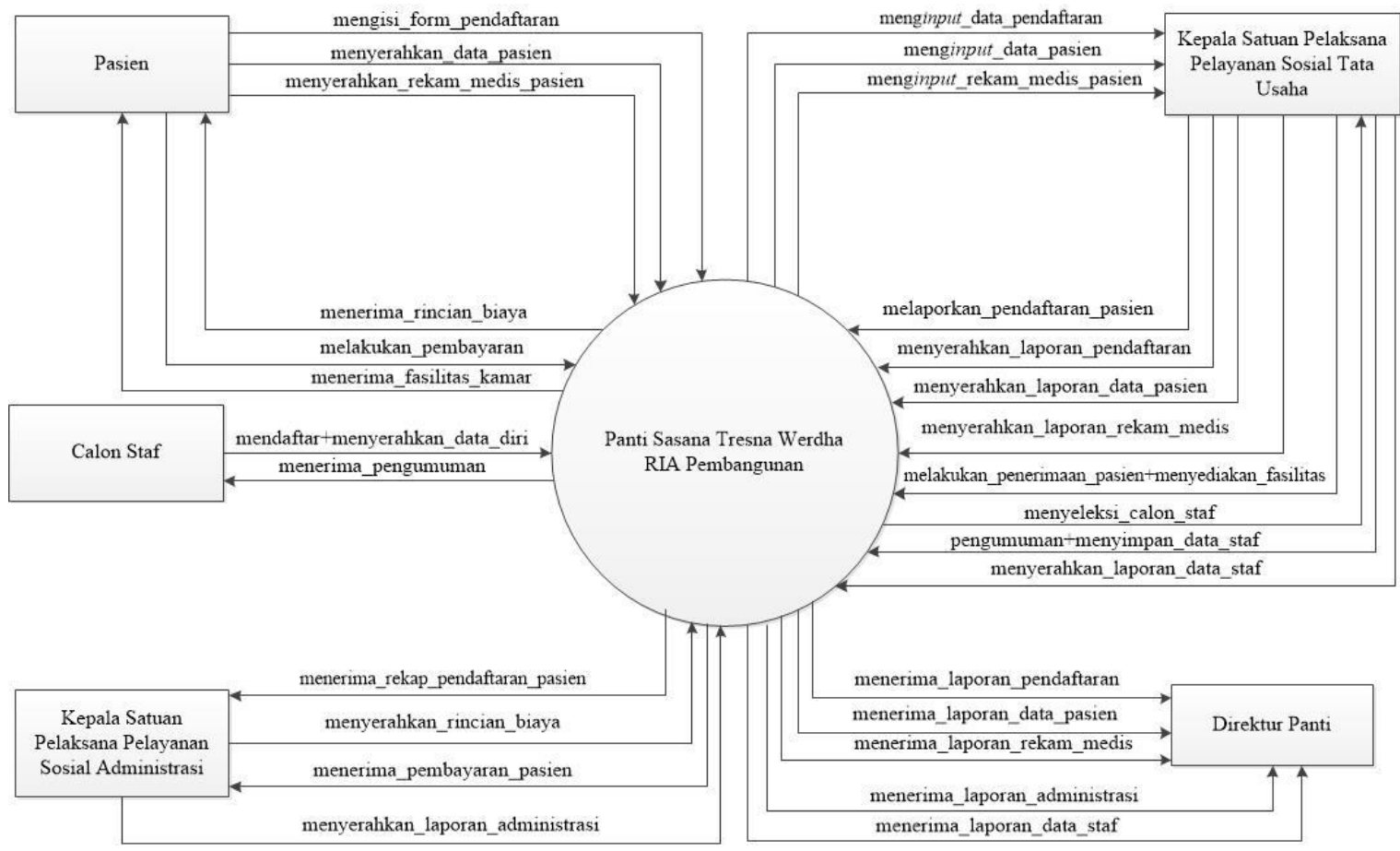

Gambar 1. Diagram Alir Data (DAD)

Entity Relationship Diagram (ERD) adalah sekumpulan cara atau peralatan untuk mendeskripsikan data-data atau objek-objek yang dibuat berdasarkan dan berasal dari dunia nyata yang disebut entitas (entity) serta hubungan (relationship) antar entitas-entitas tersebut dengan menggunakan beberapa notasi (Edi et al., 2009).

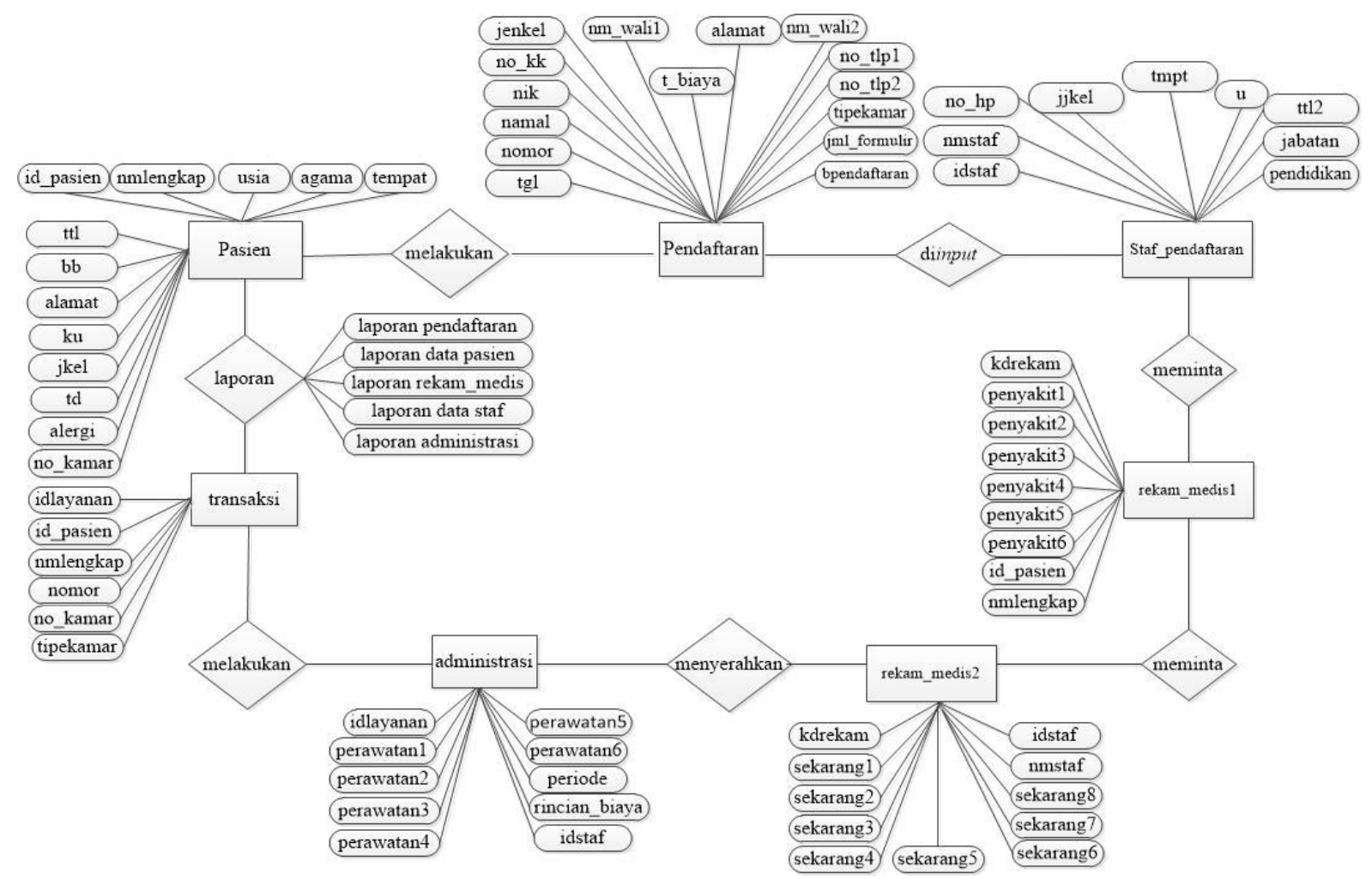

Gambar 2. Entity Relationship Diagram (ERD) 
Tampilan Layar sistem informasi pendataan pasien:

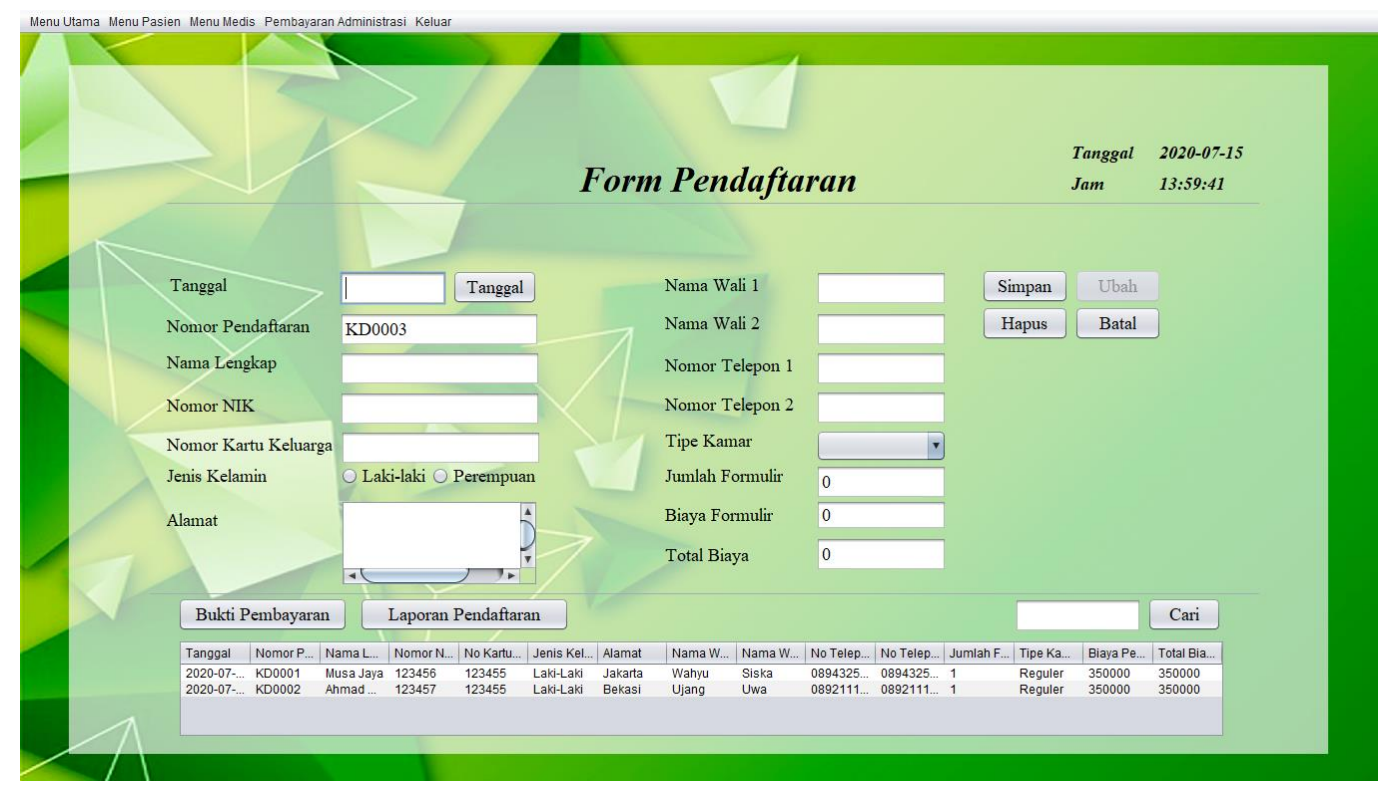

Gambar 3. Form Pendaftaran Pasien

Pada menu tampilan layar pendaftaran terdapat beberapa data yang harus diisi yang ditujukan kepada wali pasien kemudian di input langsung oleh staf untuk memaksimalkan proses pendaftaran pasien pada Sasana Tresna Werdha RIA Pembangunan.

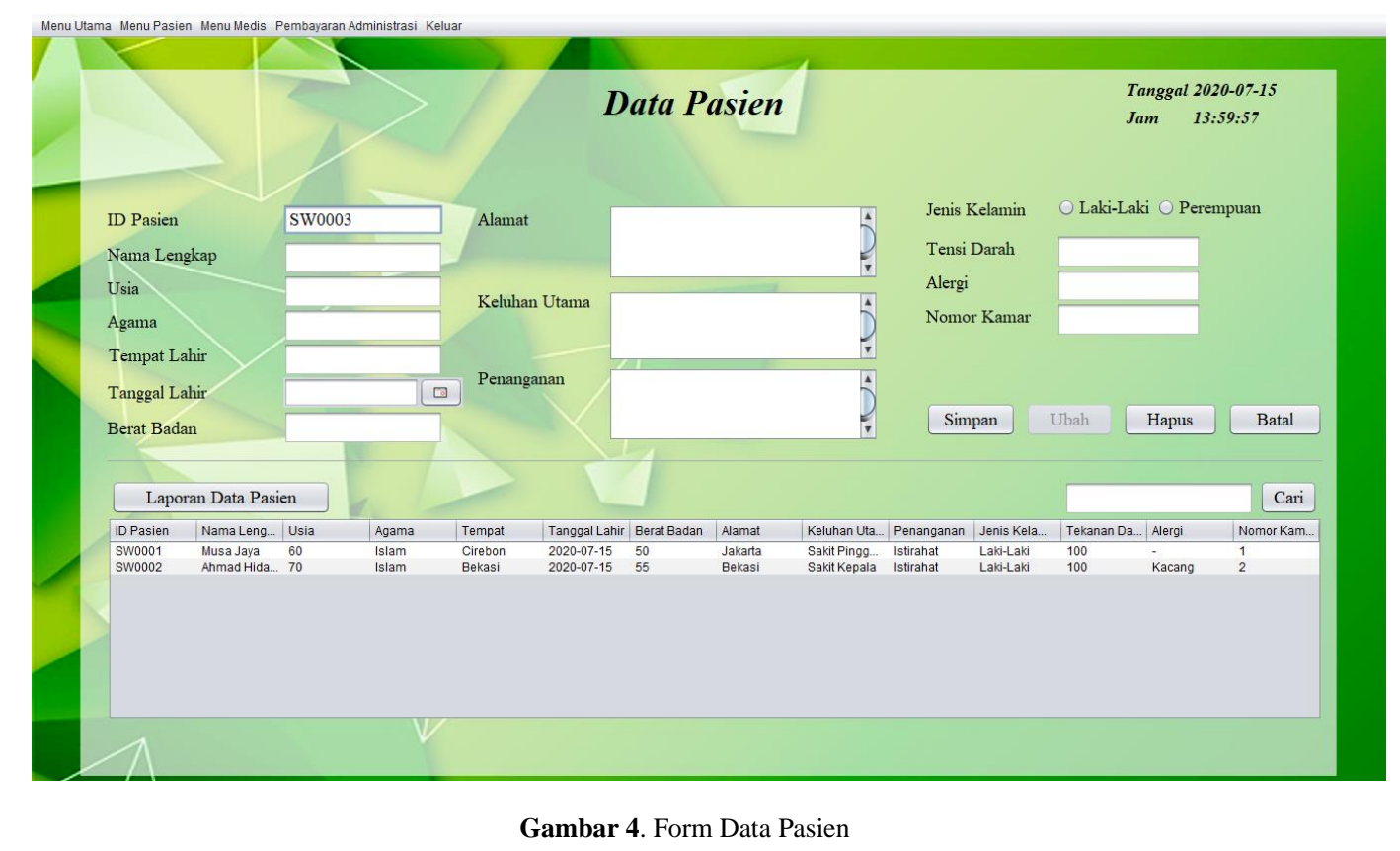

Pada Tampilan Layar pasien terdapat berbagai kolom yang digunakan untuk menginput data diri pasien yang sangat penting bagi staf ketika memerlukan informasi data diri pasien dengan penempatan action (aksi) tombol yang memudahkan staf dalam melakukan pencarian data pasien yang bersifat pribadi seperti keterangan tempat tinggal dan catatan medis utama pasien. 


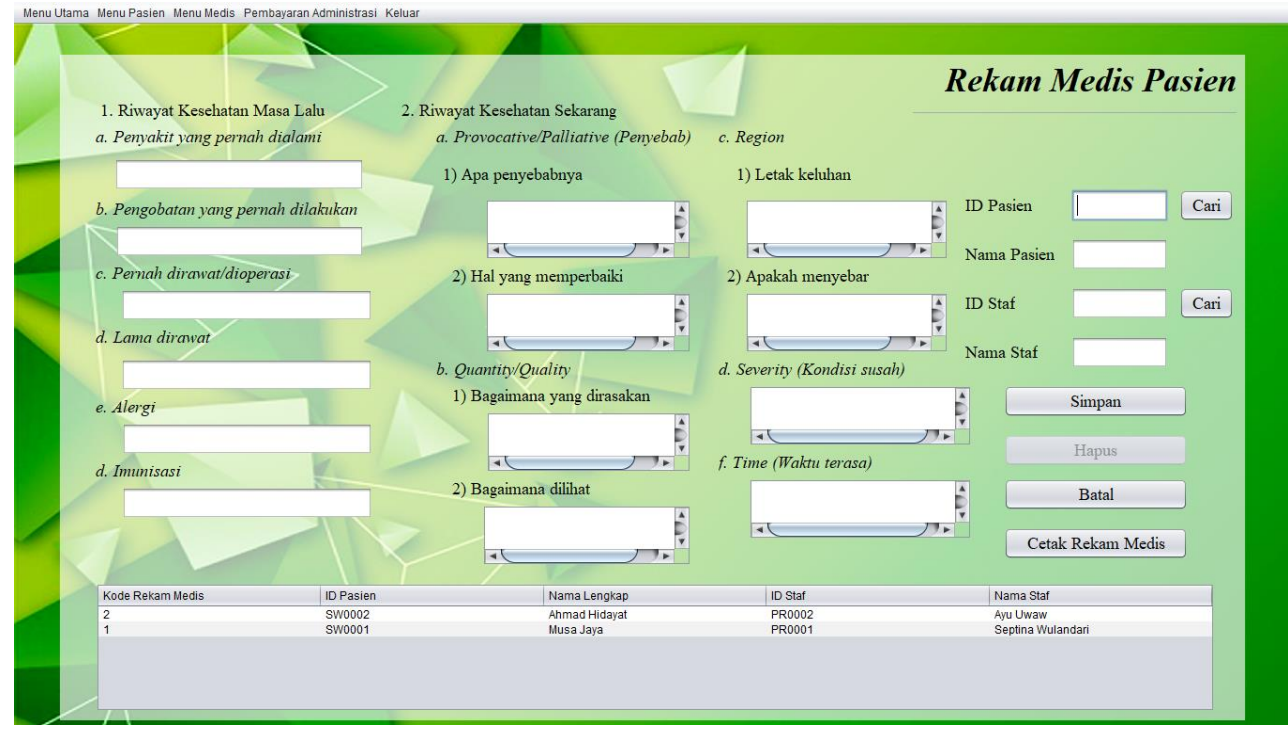

Gambar 5. Form Rekam Medis Pasien

Pada menu rekam medis dikhususkan untuk melakukan pengolahan data riwayat medis yang pernah dilakukan oleh pasien dan data yang telah diinput akan disimpan berdasarkan pemanggilan id pasien dan nama pasien. Hasil yang diperoleh melalui menu rekam medis ini berupa laporan catatan riwayat rekam rekam medis pasien yang digunakan oleh dokter dan perawat dalam menangani keluhan pasien.

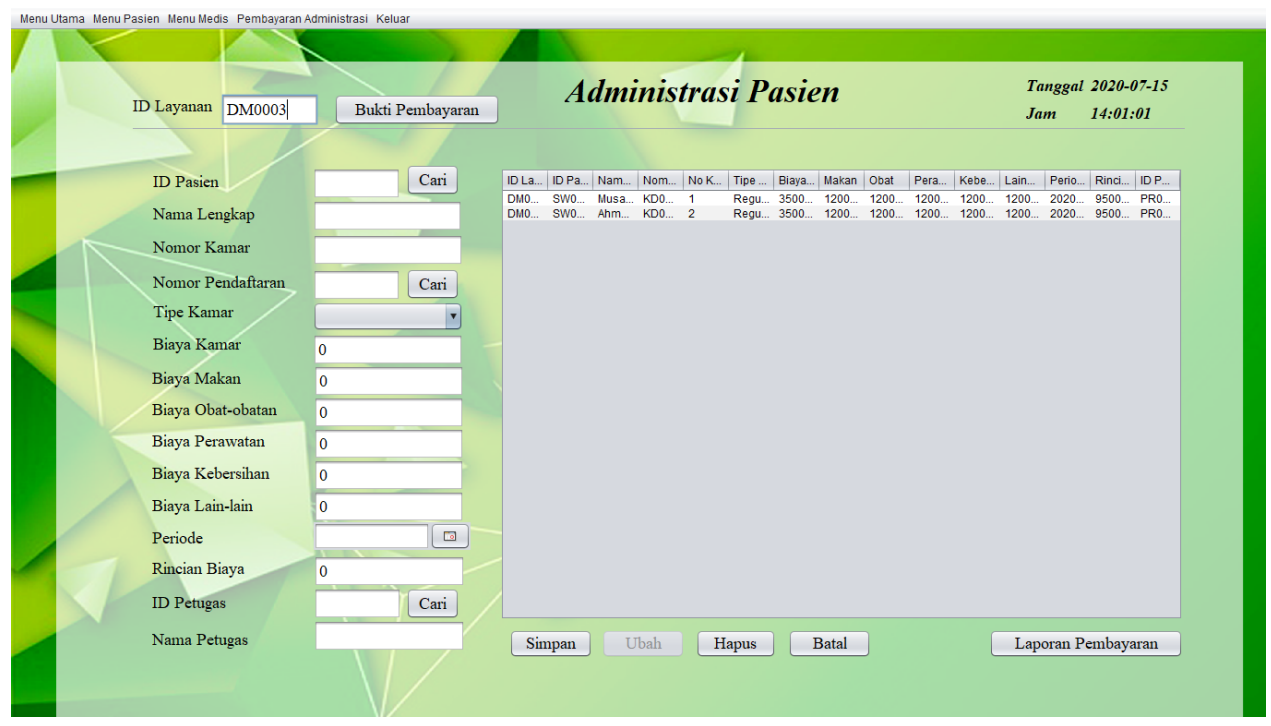

Gambar 6. Form administrasi

Melalui menu staf, pekerja (staf) yang berkerja pada Sasana Tresna Werdha Pembangunan dapat diketahui identitasnya. Pada menu staf dapat menghasilkan laporan jumlah staf dan data staf yang ada pada STW (Sasana Tresna Werdha Pembangunan) kemudian dapat diserahkan kepada kepala pimpinan Sasana Tresna Werdha Pembangunan. 


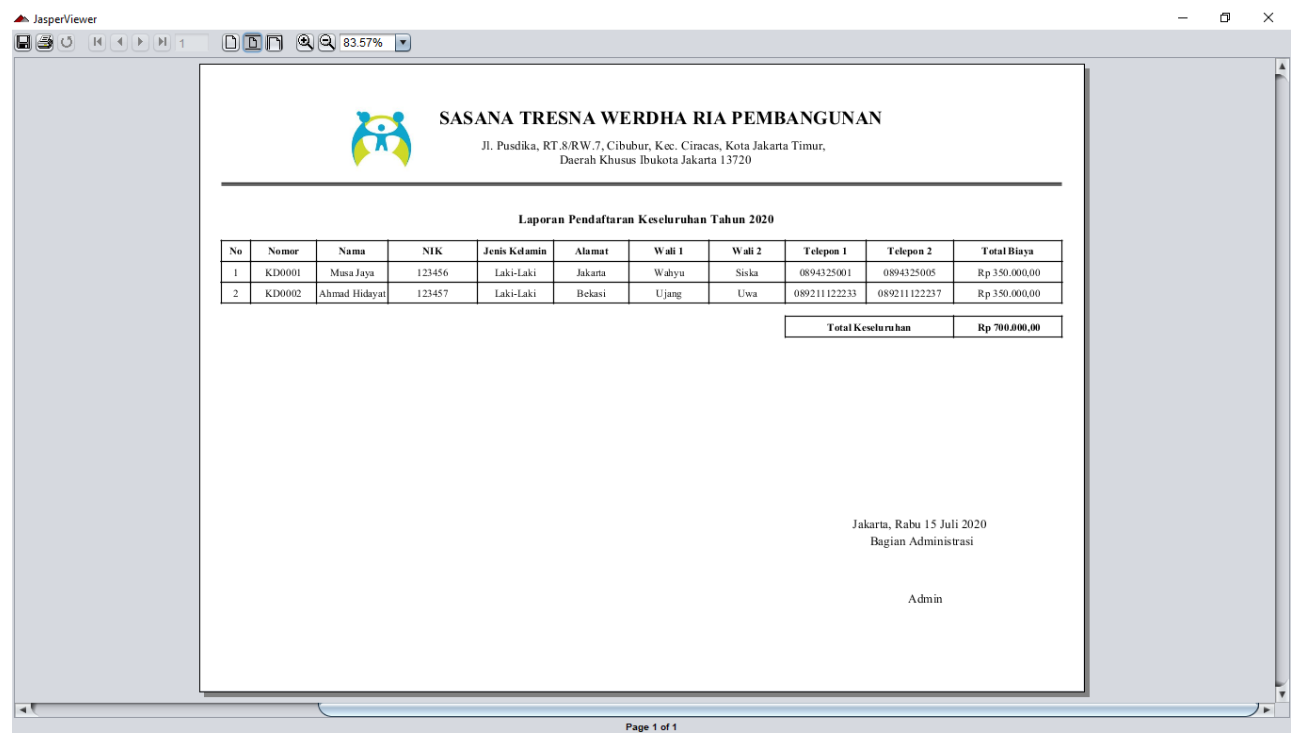

Gambar 7. Form administrasi

Pada tampilan bukti pembayaran merupakan keluaran dari menu pendaftaran untuk menjadi bukti transaksi jika calon pasien sudah melunasi pembayaran pendaftaran pasien pada Sasana Tresna Werdha Pembangunan. Bukti ini akan diserahkan kepada pasien.

\section{SIMPULAN}

Pemanfaatan teknologi di segala bidang sudah dikembangkan dengan sedemikian rupa yang bertujuan untuk membantu kinerja manusia supaya lebih cepat dibanding menggunakan cara yang bersifat tradisional. Peranan sistem informasi sangat berperan penting dalam membantu kinerja dalam pemrosesan data yang cepat dan dapat disajikan dalam sebuah laporan yang berguna bagi sebuah organisasi, perusahaan, lembaga swadaya atau yayasan yang didirikan untuk tujuan sosial seperti panti werdha. Dengan dibuatnya rancang bangun sistem informasi pendataan pasien pada sasana tresna werdha ria pembangunan berbasis Java, maka diharapkan proses pengolahan data pasien dapat terkomputerisasi dengan lebih baik. Hal tersebut bertujuan untuk meminimalisir terjadinya kerusakan berkas karena tidak tersimpan dengan baik, pencarian data yang sulit karena banyaknya data, kinerja staf yang lebih cepat dan efektif.

\section{DAFTAR PUSTAKA}

Abdur Rochman1, Rahmat Tullah2, A. R., 1, 2, 3, \& Dosen STMIK Bina Sarana Global, M. S. B. S. G. (2019). PERANCANGAN SISTEM INFORMASI DATA PASIEN DI KLINIK AULIA MEDIKA PASARKEMIS. Perancangan Sistem Informasi Data Pasien Di Klinik Aulia Medika Pasarkemis, 9(2088-1762), 1-6.

Andi Suprianto, A. A. F. M. (2018). 1), 2). Rancang Bangun Aplikasi Pendaftaran Pasien Online Dan Pemeriksaan Dokter Di Klinik Pengobatan Berbasis Web, 7(1), 48-58.

Dari, W. (2015). No Title. Penerapan Metode System Development Life Cycle Pada Pembuatan Sistem Informasi Penjualan Produk Batik Kurowo Jakarta, 3(2), 222-228.

Dindatia, N., Kesehatan, F., Universitas, M., \& Oleo, H. (2017). JURNAL ILMIAH MAHASISWA KESEHATAN MASYARAKAT. Jurnal Ilmiah Mahasiswa Kesehatan Masyarakat, 2(6), 1-9.

Edi, D., Betshani, S., Prof, J., Suria, D., \& No, S. (2009). ANALISIS DATA DENGAN MENGGUNAKAN ERD DAN MODEL KONSEPTUAL DATA WAREHOUSE. Analisis Data Dengan Menggunakan ERD Dan Model Konseptual Data Warehouse Doro, 5, 71-85.

Fadil, I., \& Ruhiat, A. (2018). SISTEM INFORMASI PENDAFTARAN DAN ANTRIAN PASIEN PADA KLINIK DOKTER MENGGUNAKAN KOMUNIKASI DATA INTERNET. 12(2).

Ferry Susanto, F., Study, P., Informatika, M., Surya, S., Ibrahim, J., No, S., \& Utara, K. L. (2018). SISTEM INFORMASI PENGOLAHAN DATA PASIEN PADA PUSKESMAS ABUNG PEKURUN MENGGUNAKAN METODE PROTOTYPE. Sistem Informasi Pengolahan Data Pasien Pada Puskesmas Abung Pekurun Menggunakan Metode Prototype, 8(1), 65-73.

Purnomo, D. (2017). Model Prototyping Pada Pengembangan Sistem Informasi. 2(2), 54-61.

Puspitasari, Y., \& Purnama, B. E. (n.d.). SISTEM INFORMASI REKAM MEDIS. Sistem Informasi Rekam Medis, 1-6.

Robi Kurniawan1), Dedi Irawan2), A. H. (n.d.). APLIKASI PENGOLAHAN DATA PENDAFTARAN REKAM. 
Jurnal Riset dan Aplikasi Mahasiswa Informatika (JRAMI)

Vol 02 No 03 Tahun Z021

e-ISSN : $2715-8756$

Aplikasi Pengolahan Data Pendaftaran Rekam Medis Pasien Menggunakan Netbeans IDE 8.2 Pada UPT Puskesmas Rawat Inap Sukadamai Natar Lampung Selatan, 1-10.

Syarifudin, G. (2018). PERANCANGAN DATABASE RELASIONAL DATA LANSIA PANTI JOMPO GRAHA KASIH BAPA KABUPATEN KUBU RAYA. Perancangan Database Relasional Data Lansia Panti Jompo Graha Kasih Bapa Kabupaten Kubu Raya, 1, 25-35. 